\title{
Multimodality imaging assessment of bicuspid aortic valve disease, thoracic aortic ectasia, and thoracic aortic aneurysmal disease
}

\author{
Preethi Mani, Reza Reyaldeen, Bo Xu \\ Section of Cardiovascular Imaging, Robert and Suzanne Tomsich Department of Cardiovascular Medicine, Sydell and Arnold Miller Family Heart \\ and Vascular Institute, Cleveland Clinic, Cleveland, Ohio, USA \\ Contributions: (I) Conception and design: P Mani, B Xu; (II) Administrative support: None; (III) Provision of study materials or patients: None; \\ (IV) Collection and assembly of data: All authors; (V) Data analysis and interpretation: All authors; (VI) Manuscript writing: All authors; (VII) Final \\ approval of manuscript: All authors. \\ Correspondence to: Bo Xu, MD, FRACP, FACC, FASE. Section of Cardiovascular Imaging, Heart, Vascular and Thoracic Institute, Cleveland Clinic, \\ Cleveland, OH 44195, USA. Email: xub@ccf.org.
}

\begin{abstract}
Acute aortic syndromes have extremely high mortality rates and those with aortic dilation are at increased risk for these often catastrophic events. Serial monitoring of patients with aortic dilation is critical to determine the appropriate timing of preventative interventions. The thoracic aorta can be imaged and measured using multiple imaging modalities including transthoracic echocardiography, transesophageal echocardiography, multidetector cardiac computed tomography, and magnetic resonance imaging. There has not been agreement on the specific techniques that should be used to measure thoracic aortic dimensions with each imaging modality, leading to potential errors and challenges in comparing changes in measurements over time. It is critical to understand the current recommendations on thoracic aortic measurements for each imaging modality and cardiovascular imaging specialists need to be explicit about the methods that they have used to derive the thoracic aortic measurements. In those at high risk for aortic pathology, such as those with connective tissue diseases or bicuspid aortic valve, a multimodality imaging strategy incorporating echocardiography including three-dimensional measurements along with cardiac computed tomography or magnetic resonance imaging should be used to establish aortic dimensions and for continued monitoring to avoid progression to acute aortic syndromes.
\end{abstract}

Keywords: Imaging; aorta; aortic aneurysm; bicuspid aortic valve (BAV)

Submitted Feb 25, 2020. Accepted for publication Mar 31, 2021.

doi: $10.21037 / \mathrm{cdt}-20-279$

View this article at: http://dx.doi.org/10.21037/cdt-20-279

Acute aortic syndromes (AAS) are often catastrophic and have high rates of mortality. Identification of those who are most vulnerable to AAS and serial monitoring of these patients with multimodality imaging is critical to prevent such events.

The aortic wall is made of a thin endothelium-lined inner intimal layer, a thick smooth muscle and elastic laminaebased media layer, and a thin collagen rich adventitia layer. The adventitia also contains the vasa vasorum, which provides nutrients to the aortic wall (1). The aorta is divided into five anatomical sections (Figure 1): the aortic root (comprised of the aortic valve annulus, aortic valve cusps, coronary ostia, and sinuses of Valsalva) (3), the tubular ascending aorta (from the sinotubular junction to the origin of the brachiocephalic artery), the aortic arch (from the brachiocephalic artery to the left subclavian artery), the descending thoracic aorta (from the left subclavian artery to the level of the diaphragm), and the abdominal aorta (from the diaphragm to the iliac bifurcation) (1).

In adults, aortic dimensions are strongly related to age 


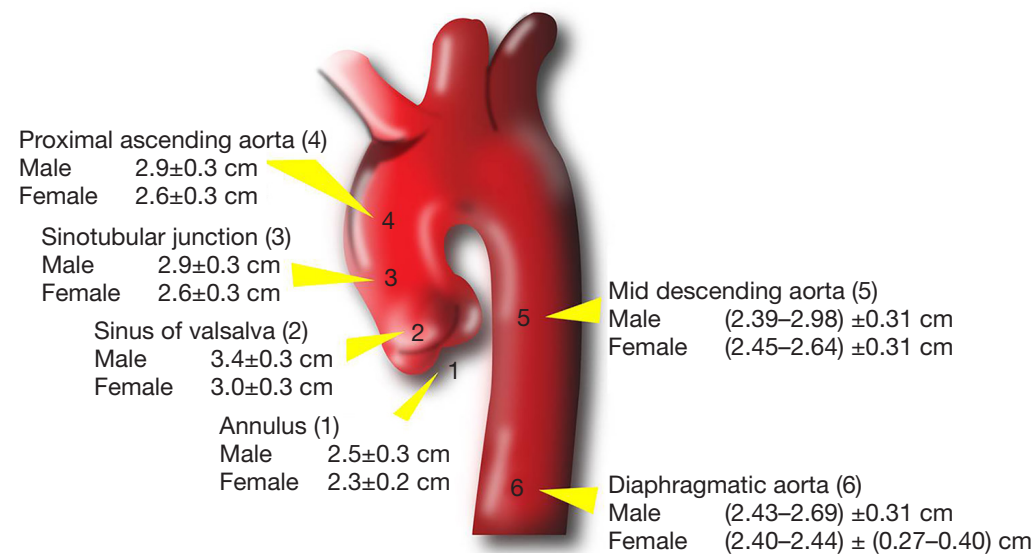

Figure 1 Normal aortic dimensions in males and females. With dimensions based on Hiratzka et al. (2).

and body size (4-10), with men having larger dimensions then women for a given age and body size $(6,11,12)$. The upper limit of normal aortic diameter is defined as two standard deviations above the mean predicted diameter (Z score $\geq 2)(1)$.

\section{Thoracic aortic aneurysms (Table 1)}

The accepted definition for an aneurysm is a permanent focal dilatation of an artery with a $\geq 50 \%$ increase in diameter compared to the expected normal diameter $(2,15)$. Ectasia is defined as arterial dilatation $<150 \%$ of the normal arterial diameter, while arteriomegaly is diffuse arterial dilatation involving several arterial segments, with an increase in diameter $>50 \%$ compared to expected (2). Aortic dilatation is a broader term which encompasses ectasia and aneurysm. True thoracic aortic aneurysms involve all three layers of the aortic wall; $60 \%$ affect the aortic root and/or ascending aorta, $40 \%$ the descending aorta, $10 \%$ the arch, and $10 \%$ the thoracoabdominal aorta (16). Aneurysms may be fusiform or saccular in morphology. Fusiform aneurysms are a result of diffuse weakening of the aortic wall, leading to dilatation of the entire circumference of the aorta, while in saccular aneurysms, only a portion of the aortic circumference is weakened, leading to a focal ballooning.

Aortic dimension is the most important predictor of aortic rupture or dissection (17). Aneurysms $<50 \mathrm{~mm}$ in diameter have a mean rupture rate of $2 \%$ /year, those $50-59 \mathrm{~mm}$ in size have a rupture rate of $3 \% / y e a r$, and those $\geq 60 \mathrm{~mm}$ have a rupture rate $7 \% / y e a r(17)$. The average rate of growth for ascending aneurysms is $0.07 \mathrm{~mm} /$ year, whereas those in the descending aorta grow at $1.9 \mathrm{~mm} /$ year (18). Those with known aneurysms should be monitored closely with serial imaging to determine optimal timing of surgical intervention. In asymptomatic patients with aneurysms and those approaching the threshold for surgical intervention, imaging should be performed every 6 months until the surgical threshold is reached or the dimensions remain stable (at which time annual or less often surveillance is sufficient). Patients with isolated arch aneurysms less than $4.0 \mathrm{~cm}$ should be monitored with cardiac computed tomography (CT) or magnetic resonance imaging (MRI) every year, while those with dimensions greater than $4.0 \mathrm{~cm}$ should have imaging every 6 months (2).

Aortic sizes are typically indexed to body surface area (BSA) (19), though it has been proposed that indexing to height may be more appropriate than BSA especially in obese subjects. Ascending aorta to height ratio has been shown to be independently associated with cardiovascular death (20). The latest American College of Cardiology (ACC)/American Heart Association (AHA) guidelines include a class IIa recommendation for elective aortic replacement in those with Marfan syndrome, bicuspid aortic valve (BAV), or other genetic diseases when the ratio of maximal ascending aorta or aortic root area in $\mathrm{cm}^{2}$ divided by the patient's height in meters is greater than 10 (2). Recommendations for use of area/height ratio in patients without these conditions are less clear, although a ratio of aortic root to height in patients with a tricuspid aortic valve has been shown to provide risk stratification for death (21).

The major risk factors for development of thoracic aortic aneurysms are hypertension, smoking, and chronic obstructive pulmonary disease (COPD). Common genetic causes of aneurysms are further discussed below. Per the ACC/AHA guidelines, in asymptomatic patients with 
Table 1 Guideline recommendations for thoracic aortic disease adapted from the American College of Cardiology (ACC)/American Heart Association (AHA) and the European Society of Cardiology (ESC)

\begin{tabular}{|c|c|c|}
\hline $\begin{array}{l}\text { Type of disease and associated } \\
\text { conditions }\end{array}$ & ACC/AHA 2010/2016, (2) & ESC 2014, (13) \\
\hline \multicolumn{3}{|c|}{ Ascending aorta without associated condition } \\
\hline AVR indicated & Replace aorta if $\geq 4.5 \mathrm{~cm}$ & Replace aorta if $\geq 4.5 \mathrm{~cm}$ \\
\hline \multicolumn{3}{|c|}{ Bicuspid aortic valve associated aortopathy } \\
\hline Surgical evaluation & $\begin{array}{l}\geq 5.5 \mathrm{~cm} \text { (consider at } 5 \mathrm{~cm} \text { if risk factors - family } \\
\text { history of dissection, growth } \geq 0.5 \mathrm{~cm} / \text { year or } \\
\text { low risk patient at experienced aortic center); } \\
\text { aortic area/height ratio }>10 \mathrm{~cm}^{2} / \mathrm{m}(14)\end{array}$ & $\begin{array}{l}\geq 5.5 \mathrm{~cm} \text { (consider } \geq 5 \mathrm{~cm} \text { if risk factors - } \\
\text { family history, hypertension, coarctation of } \\
\text { the aorta or growth rate }>3 \mathrm{~mm} / \text { year) }\end{array}$ \\
\hline \multicolumn{3}{|l|}{ Genetic/connective tissue disease } \\
\hline \multicolumn{3}{|l|}{ Marfan syndrome } \\
\hline Surgical evaluation & $\begin{array}{l}\text { Consider between } 4-5 \mathrm{~cm} \text { (lower threshold if } \\
\text { growth }<0.5 \mathrm{~cm} / \text { year, family history of dissection } \\
\text { or significant aortic regurgitation): aortic area/ } \\
\text { height ratio }>10 \mathrm{~cm}^{2} / \mathrm{m}\end{array}$ & $\begin{array}{l}\geq 5 \mathrm{~cm} \text { (consider } \geq 4.5 \mathrm{~cm} \text { if family history } \\
\text { of dissection, growth }>3 \mathrm{~mm} / \text { year, severe } \\
\text { aortic regurgitation) }\end{array}$ \\
\hline Women contemplating pregnancy & $\geq 4 \mathrm{~cm}$ & $\geq 4 \mathrm{~cm}$ \\
\hline \multicolumn{3}{|l|}{ Loeys-Dietz syndrome } \\
\hline
\end{tabular}

AVR, aortic valve replacement; CT, computed tomography; MRI, magnetic resonance imaging; TEE, transesophageal echocardiogram.

ascending aorta or sinus diameter greater than $5.5 \mathrm{~cm}$, surgery should be considered. In those who have growth rate of more than $0.5 \mathrm{~cm} /$ year, surgery may be considered even if dimensions are less than $5.5 \mathrm{~cm}(1,2)$. For patients who are undergoing aortic valve surgery, concomitant aortic root repair or replacement should be considered in those with dimensions greater than $4.5 \mathrm{~cm}$ (2).

\section{BAV (Figure 2)}

$\mathrm{BAV}$ is the most common congenital cardiac abnormality, with a prevalence of $0.46 \%$ to $1.37 \%$ in the population
(22-25). BAV is associated with an increased risk of ascending aortic aneurysms, with prevalence ranging from $7.5 \%$ to $59 \%$ at the annulus, $16 \%$ to $78 \%$ at the Sinus of Valsalva, $15 \%$ to $79 \%$ at the sinotubular junction, and $35 \%$ to $68 \%$ at the proximal ascending aorta (26-29). Aortic dilatation increases with age, with dilatation noted in $56 \%$ of those less than 30 years of age, but in up to $88 \%$ of those $>80$ years of age (30). This burden of BAV aortopathy leads to prophylactic ascending aorta replacement in approximately one-fourth of BAV patients (31), with a surgical expense in the US alone exceeding 1 billion dollars/year (32).

The pathophysiology of aortopathy in BAV is related 


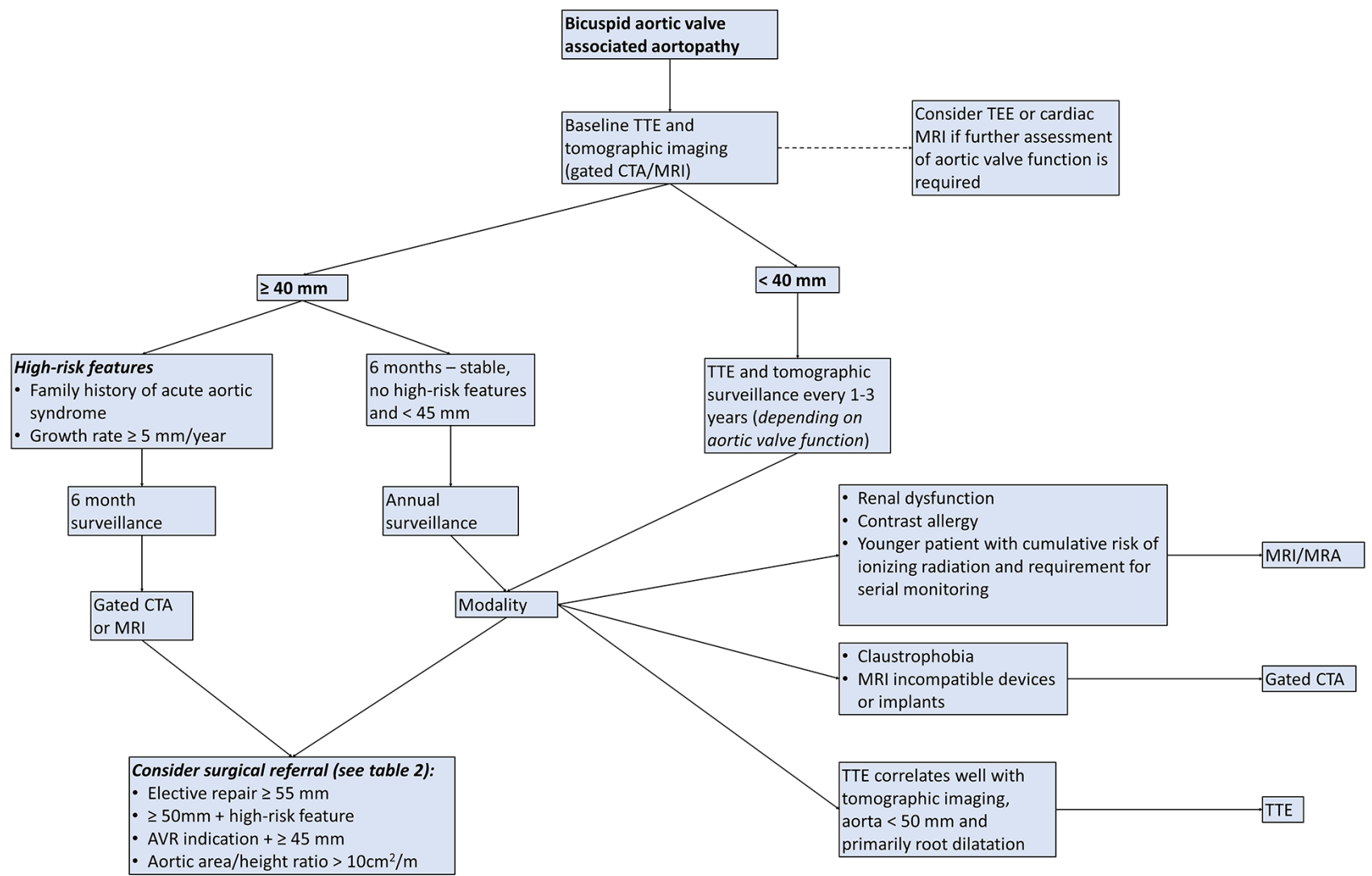

CTA-Computed tomographic aortography; MRI - magnetic resonance imaging; MRA - magnetic resonance angiography; TTE - transthoracic echocardiogram; TEE - Transesophageal echocardiogram

Figure 2 Screening and management of bicuspid valve related aortopathy.

to medial degeneration, with the distance between elastic lamellae in BAV being greater than in tricuspid aortic valves, while the lamellae are also thinner and more fragmented (33-35). BAV patients have also been shown to have higher rates of vascular smooth muscle cell apoptosis even in those without aortic dilation $(33,36,37)$. BAV aortic tissue has been shown to have decreased fibrillin-1 content, leading to smooth muscle cell detachment from elastin and collagen that results in apoptosis and worse structural integrity. Matrix metalloproteins are also overexpressed and have increased activity in BAV aneurysms compared to idiopathic aneurysms (38-42).

Prior studies have shown the rate of ascending aorta growth in BAV patients to be 0.2 to $1.9 \mathrm{~mm} /$ year $(17,29,43-45)$, with an exponential growth curve (43,46-48). The increase in aortic dimensions in BAV has been shown to be significantly faster $(17,49)$ and the age of presentation of aortic dilation is significantly younger in those with BAV compared to tricuspid aortic valve $(17,44)$.

The rates of dissection and rupture of $\mathrm{BAV}$-associated ascending aortic aneurysms are comparable to aneurysms of other etiologies (50-52). Studies in patients with BAV have shown that there is an 8 to 9 times higher risk of dissection in those with BAV compared to the general population $(31,53)$.

Per the 2016 ACC/AHA clarification statement, elective surgical repair of the aortic root or ascending aorta is indicated when dimensions reach $5.5 \mathrm{~cm}$ (14). This differs from prior statements, when surgery at $5.0 \mathrm{~cm}$ was recommended (54). Given somewhat conflicting evidence on when the risk of aortic dissection increases greatly, the recommendations are now more conservative. In those with root or ascending aorta dimensions $5.0 \mathrm{~cm}$ or greater or with an additional risk factor such as family history of dissection or aortic growth of $\geq 0.5 \mathrm{~cm} /$ year, or in a low-risk patient at an experienced 


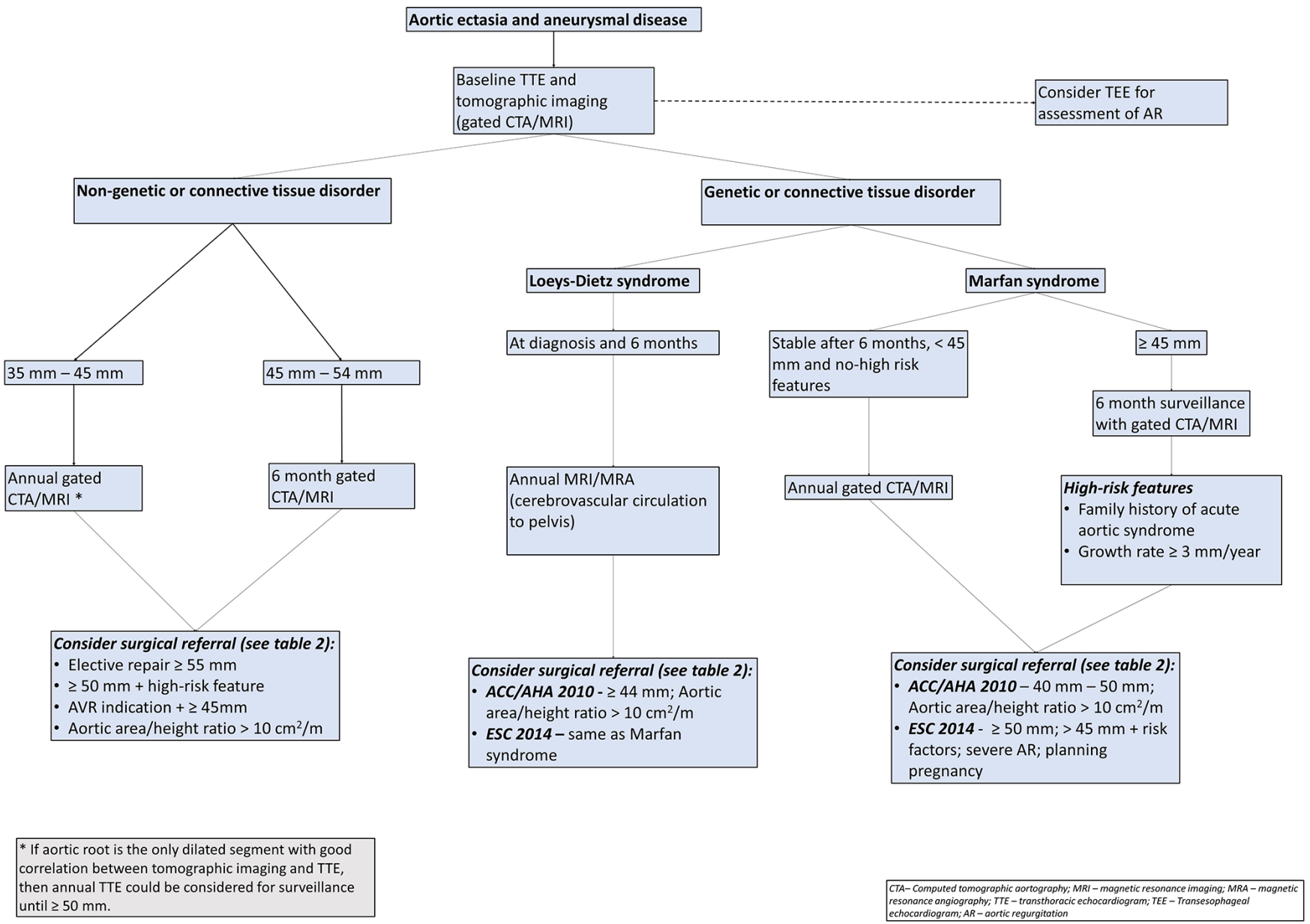

Figure 3 Screening and management of connective tissue disease-related aortopathy and other non-connective tissue disorder-related aortopathies.

surgical center, surgery is reasonable (2) (Figure 2). In those undergoing aortic valve replacement (AVR) for BAV stenosis or regurgitation, ascending aorta replacement is reasonable at $4.5 \mathrm{~cm}$. According to the American Society of Echocardiography (ASE)/European Association for Cardiovascular Imaging (EACVI) guidelines, if there is no aortopathy noted by transthoracic echocardiography (TTE), repeat TTE should be done every 3-5 years to assess root and proximal aortic size, and tomographic imaging with cardiac CT or MRI should be done every $3-5$ years to assess the arch and descending aorta (1). Once aortic dimensions are noted to be $>4.0 \mathrm{~cm}$ in a $\mathrm{BAV}$ patient, at least annual monitoring of aortic dimensions are indicated. Specifically, repeat imaging should be done 6 months after initial identification of ascending aortic enlargement. If aortic size is stable, $<45 \mathrm{~mm}$, and there is no personal or family history of dissection, annual imaging is recommended (1). Given these recommendations, accurate measurement of aortic dimensions using multi-modality imaging is critical to identify patients who should undergo surgical repair.

\section{Connective tissue diseases (Figure 3)}

Marfan syndrome, an inherited connective tissue disease caused by a mutation in the fibrillin $(F B N 1)$ gene, is primarily associated with dilatation or dissection of the aortic root or proximal ascending aorta $(1,2)$. In those Marfan syndrome patients with aortic root enlargement, repeat imaging in 6 months is recommended (Figure 3). If the size is stable and $<45 \mathrm{~mm}$ on this repeat study with no family or personal history of dissection, annual aortic imaging should be pursued (2). Higher risk patients, such 
as those with a measurement $>4.5 \mathrm{~cm}$ or with significant growth, should be monitored every 6 months (2). Patients with Marfan syndrome who are considering pregnancy can be considered for surgery if root or ascending aorta diameter is greater than $4.0 \mathrm{~cm}$ (2). Otherwise, surgical repair is usually performed at a threshold of $5.0 \mathrm{~cm}$, given the relatively low risk of dissection at lower diameters $(2,55,56)$. At an experienced center of excellence, elective surgical repair may be considered in Marfan syndrome when the thoracic aortic dimension exceeds $4.5 \mathrm{~cm}$. In those who have had ascending aorta repair, continued monitoring of the arch and descending aorta is still recommended.

Loeys-Dietz syndrome is caused by a gene mutation in transforming growth factor beta (TGF $\beta 1$ or 2 ) and has an autosomal-dominant inheritance pattern (57). The majority of Loeys-Dietz patients have aortic root aneurysms and may also have aneurysms of other aortic segments and tortuous vessels $(57,58)$. Dissection can occur at smaller dimensions in Loeys-Dietz patients compared to other connective tissue diseases and thus monitoring should occur every 6 months rather than annually (2). Furthermore, patients with LoeysDietz syndrome are recommended to have yearly MRI imaging from the cerebrovascular circulation to the pelvis (2). Surgical repair is reasonable at $4.2 \mathrm{~cm}$ by transesophageal echocardiogram (TEE) or 4.4 to $4.6 \mathrm{~cm}$ by CT/MRI (2). At an experienced center of excellence, elective surgical repair may be considered in Loeys-Dietz syndrome, when the thoracic aortic dimension reaches $4.5 \mathrm{~cm}$ or greater.

Ehlers-Danlos syndrome type IV (vascular form) is an autosomal dominant disorder associated with arterial dilatation and rupture (2). Recommendations for monitoring of aortic dimensions are not clear, as surgery is high risk due to tissue fragility. Patients with Ehlers-Danlos of the non-vascular form often have aortic root dilation but progression to dissection is uncommon $(59,60)$.

\section{Multimodality imaging of thoracic aortic disease (Figure 4)}

\section{TTE}

The cornerstone of cardiac imaging remains the TTE, which is often the first test used to screen for and measure aortic dilatation. TTE can provide clear visualization of the aortic root and proximal ascending aorta. The best windows to measure the proximal ascending aorta are the left and right parasternal long axis views, with measurements taken perpendicular to the plane of the aorta (1). The ascending aorta can also be visualized in the apical three-chamber and apical five-chamber views. Standard convention is to measure leading edge to leading edge in end diastole $(2,61,62)$, which is how most reference values have been reported. This was primarily chosen due to initial challenges in identifying the tissue blood interface (63) on echocardiography; however, the technology has improved enough since, and this is less of a limitation now. The current ASE guidelines, however, still advocate for end-diastolic leading edge to leading edge measurements perpendicular to the long axis of the aorta (1). Recent ACC/AHA guidelines (2), on the other hand, recommend measuring from inner edge to inner edge. While two-dimensional (2D) TTE reference values for inner edge to inner edge measurements of the aorta have now been published based on large adult population studies (64), measurement using the leading edge to leading edge technique continues to be most common method of determining aortic measurements by 2D TTE.

Measurements by TTE should be made from 2D images rather than M-mode, which can underestimate dimensions by 1 to $2 \mathrm{~mm}$ (62). The aortic annulus should be measured at the hinge points of the aortic valve cusps (inner edge to inner edge) in the parasternal long axis view during systole (62). The sinuses and sinotubular junction should be measured at end diastole as previously described. The aortic arch is best visualized from the suprasternal window, where portions of the ascending and descending aortas are also seen. Evaluation of the descending thoracic aorta may be challenging by TTE.

\section{TEE}

Due to higher frequency transducers and proximity of the esophagus to the thoracic aorta, TEE can often provide superior assessment of the thoracic aorta compared to TTE (1). One major advantage of TEE is that almost the entire thoracic aorta can be imaged except for a small area of the distal ascending aorta near the innominate artery. The ascending aorta is best visualized in the mid-esophageal long axis view at $100^{\circ}$ to $140^{\circ}$, a view analogous to the parasternal long-axis view. Short-axis views of the aortic root and ascending aorta can be obtained at $45^{\circ}$ to $60^{\circ}$ with anteflexion of the probe. The descending thoracic aorta can be visualized in short axis by rotating posteriorly from a mid-esophageal four chamber view at $0^{\circ}$. Withdrawal of the probe allows for imaging of the more proximal descending aorta and aortic arch. Adjusting the angle to $90^{\circ}$ results in a short-axis view of the transverse arch (65). 

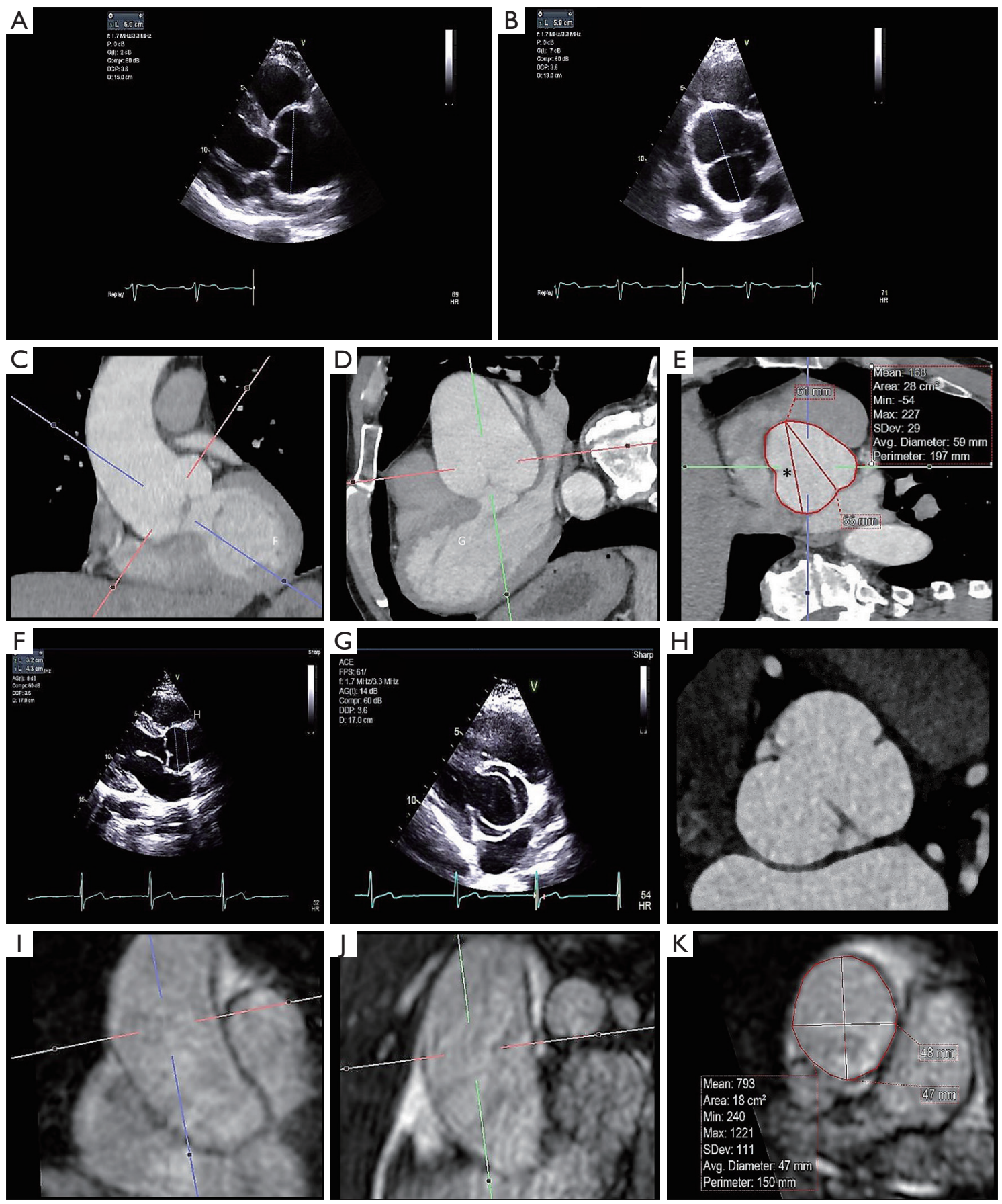

Figure 4 Thoracic aortic measurements by echocardiography, cardiac CT, and MRI. (A) Transthoracic echography parasternal long-axis view, showing aortic sinus leading edge to leading edge measurement. (B) Transthoracic echocardiography-parasternal short-axis view at the aortic valve/root level, showing sinus measurement. (C) Cardiac CT aortic root coronal view. (D) Cardiac CT aortic root sagittal view. (E) CT aortic root short-axis view derived from double oblique planes (shown in C and D). Measurements show sinus to sinus $\left(^{*}\right.$ ) and sinus to commissure measurement methods. (F) Transthoracic echocardiography parasternal long-axis view, showing aortic sinus and sinotubular junction measurements. $(G)$ Transthoracic echocardiography parasternal short-axis view, showing a bicuspid aortic valve with fusion between the left and right coronary cusps. (H) Cardiac CT scan image demonstrating a bicuspid aortic valve with fusion between the left and right coronary cusps. (I) MRI coronal view of the ascending aorta. (J) MRI sagittal view of the ascending aorta. (K) MRI short-axis view derived from double oblique planes (shown in I and J). CT, computed tomography; MRI, magnetic resonance imaging. 
While visualization of aortic segments is typically easy by TEE, evaluation can be limited in the setting of significant aortic tortuosity. Furthermore, TEE can sometimes be prone to artefacts, such as linear horizontal lines that move in parallel with the aorta or a pseudo-double barrel aorta (66).

\section{D echocardiography}

3D TTE or TEE can help to determine if 2D measurements represent the maximal dimensions of the aorta. 3D techniques can help ensure that the correct non-foreshortened crosssectional planes are measured and allows for confirmation that 2D measurements represent maximal dimensions (67). Use of 3D multiplanar reconstruction to determine maximal dimensions allows for very accurate analyses of most segments and can help account for asymmetry in portions of the thoracic aorta (67). 3D TEE based measurements have been shown to have strong agreement with contrast CT aortic measurements (68) and may be especially useful in those patients who cannot receive contrast. The major limitation of $3 \mathrm{D}$ echocardiography is that $3 \mathrm{D}$ acquisition quality depends on 2D image quality and thus may not be optimal in all patients. Accurate $3 \mathrm{D}$ measurements also require familiarity with the techniques and thus should be obtained whenever feasible so that cardiovascular imaging specialists can gain expertise in interpreting these images. Given the potential additional information that can be obtained from 3D echocardiography in addition to standard 2D echocardiography, the use of $3 \mathrm{D}$ techniques is recommended with echocardiography (both TTE and TEE) for the most accurate results.

\section{$C T$}

Electrocardiographically (ECG)-gated computed tomographic aortography (CTA) using a multidetector CT (MDCT) scanner with $\geq 64$ detector rows is the preferred CT imaging method for the thoracic aorta. MDCT can provide high spatial resolution images with modest radiation exposure, with a scan time of only a few seconds $(2,69)$. In addition, CTA allows for simultaneous imaging of vascular structures such as the vessel wall (70). In some cases, ECG-gated CTA allows for high quality ascending aorta imaging with concurrent evaluation of the coronary arteries. ECG-gating also eliminates motion and other artifacts, increasing the accuracy of diagnosis and allowing for measurement of maximal dimensions (71).

While cardiac CT does have the disadvantages of ionizing radiation use and use of iodinated contrast, careful acquisition methods can reduce the amount of radiation received by the patient, and proper hydration and choice of low-osmolar contrast can reduce the risk of contrast associated nephropathy $(72,73)$. Non-contrast CT may also be sufficient for monitoring of aortic dimensions. However, especially in young male and premenopausal female patients, use of MRI or echocardiography may be preferred for serial monitoring scans.

CTA clearly shows the aortic wall and thus measurement of both inner-inner and outer-outer diameters are possible. Similar to echocardiographic measurements, there is some inconsistency between recommendations on measuring aortic dimensions using CTA. While the ACC/AHA and Society of Thoracic Surgeons (STS) guidelines recommend using outer to outer dimensions (2,74), the ASE guidelines advocate for inner-to-inner measurements for the ascending aorta and outer to outer for the descending aorta (1). The most precise method for measurement relies on the use of multiplanar reconstruction of the axial data to create aortic images perpendicular to the aortic lumen (the double-oblique method). This method accounts for shape distortions and allows measurement of both major and minor dimensions.

There has been some degree of inconsistency in the timing of thoracic aortic measurement by cardiac CT and also how these measurements should be optimally made. Thoracic aortic diameters are largest in end systole $(5,75)$ but images at end diastole are less prone to motion artifact (76). Further, a consensus has not been reached whether MDCT/MRI measurements should be made from sinus to sinus or sinus to commissure. Sinus to sinus measurements have been shown to be about $2 \mathrm{~mm}$ larger than sinus to commissure in a study of 70 patients, though patients with sinus asymmetry were excluded from this study (77). Sinus asymmetry is especially common in those with a BAV, with the non-coronary sinus being frequently larger (78).

\section{MRI}

MRI can provide reliable information on thoracic aortic dimensions without ionizing radiation and in many cases, without gadolinium-based contrast. MRI remains a versatile modality to image the thoracic aorta and is a particularly attractive option for younger patients requiring surveillance for aortic disease due to the absence of ionizing radiation. Non-contrast techniques were the first sequences used with early ECG-gated spin-echo sequences, having the 
ability to accurately measure thoracic aortic dimensions and detect dissection (79). Breath holding is now standard which reduces respiratory motion and subsequent artefact. These "black blood" images are often performed first to determine aortic shape and size, and with nulling of signal from moving blood, the aortic wall can be delineated clearly $(13,80)$. This sequence can also detect slow flow such as within a false lumen in a dissection (13). Noncontrast aortic imaging has seen ongoing development and improvement with balanced steady-state free-precession (bSSFP) sequences which utilize intrinsic differences of T2/ T1 ratios in various tissue (81). Since blood has a high T2/ $\mathrm{T} 1$ ratio compared to other tissue, this technique allows for bright-blood images without contrast administration, although this will occur in both the arterial and venous systems. This technique may be limited in areas of high turbulence which creates a heterogenous blood pool and resultant artefact (80). 3D rendering can also be obtained in this sequence, similar to contrast-enhanced (CE) magnetic resonance angiography (MRA), and has comparable accuracy (82).

"Fresh blood imaging" is another non-contrast technique where two ECG triggered 3D fast (turbo) spin-echo sequences are performed, with the first gated to systole and the second to diastole and resultant subtraction of the systolic acquisition yielding an arterial-only dataset (83). This technique relies on fast arterial flow losing signal during systole compared to the constant signal from slow diastolic flow and the constant bright venous flow which lacks pulsatility (84). Bright-blood MRA is then obtained through subtraction which is dependent on adequate ECG gating and timing, but can be difficult to achieve in patients with arrhythmia. Another common technique used to image the aortic lumen is CE-MRA which utilizes gadolinium-based contrast through peripheral injection with preferential arterial enhancement (85). Breath-holding for 20 seconds is ideal, and the ability to construct a $3 \mathrm{D}$ angiogram is particularly useful with multiplanar analysis being able to accurately measure aortic diameter in a true perpendicular plane (80). One additional method for aortic imaging is non-contrast 3D whole heart MRA, which is a respiratory and cardiac gated, fat-suppressed, 3D-balanced SSFP sequence (86). This technique has been shown to have $100 \%$ diagnostic accuracy and similar reader confidence compared with CEMRA of the thoracic aorta, with superior image quality at the aortic root and ascending aorta (82,86-88). Given the reliability of these sequence for diagnostic evaluation without the need for contrast, non-contrast 3D whole heart MRA should be considered the standard MRA sequence for most patients. Finally, phase contrast sequences can be used to quantify aortic flow, and relies on the principle that protons passing through a magnetic field undergo phase change relative to velocity (89). This allows functional assessment and quantification of aortic valve pathology (stenosis and regurgitation), coarctation and other valvular regurgitation if necessary. With ongoing developments in MRI techniques particularly non-contrast methods, shorter acquisition times and improved spatial resolution, MRI remains an important modality for aortic assessment.

\section{Comparisons between imaging modalities (Table 2)}

To assess for the presence of thoracic aortic aneurysms or to get the most accurate measurements of the thoracic aorta, CTA or MRA are the preferred imaging modalities, as they both image all of the segments of the thoracic aorta. With CTA and MRA, the use of multiple planar views leads to the most accurate imaging assessment of aortic dimensions. The sensitivity and specificity of these two methods are similar $(16,90)$, with the main advantages of MRA being lack of ionizing radiation and no need for iodinated contrast. However, CTA is more readily available and has shorter acquisition time compared to MRA and is typically the imaging technique of choice for staging and surveillance of the aorta. If the area of interest is the aortic root, TTE may provide optimal imaging as motion artifact on non-gated CTA often precludes optimal root assessment. If agreement between aortic root and proximal ascending aorta dimensions by TTE and CTA/ MRA has been established, serial TTE can be used for monitoring.

Given the need for repeated aortic measurements over time, it is important to optimize protocols with the goal of minimizing inter-reader and intra-reader variability. A study of multimodality imaging from the GenTAC registry (consisting of 965 studies of subjects with genetic conditions predisposing to aortic aneurysm, rupture, or dissection) showed that the variability in initial reads was higher for CT and MRI compared to echocardiography (91), primarily due to lack of consistent ECG gating. Specifically, TTE was more reproducible at the proximal segments, while CT and MRI were more reproducible at the arch and descending segments. Measurements should be made relative to anatomical landmarks to ensure reproducibility. The authors call for unified acquisition protocols for CT and MRI, which currently do not exist across different 
Table 2 Comparison of imaging modalities for assessment of aortic dimensions

\begin{tabular}{|c|c|c|}
\hline Modality & Strengths & Weakness \\
\hline \multirow{3}{*}{$\begin{array}{l}\text { Transthoracic } \\
\text { echocardiogram (TTE) }\end{array}$} & Readily available & \multirow{3}{*}{$\begin{array}{l}\text { Cannot reliably image ascending aorta, arch, or } \\
\text { descending aorta }\end{array}$} \\
\hline & No radiation & \\
\hline & Excellent reproducibility of measurements & \\
\hline \multirow{2}{*}{$\begin{array}{l}\text { Transesophageal } \\
\text { echocardiogram (TEE) }\end{array}$} & \multirow{2}{*}{$\begin{array}{l}\text { Evaluation of most segments of thoracic aorta } \\
\text { possible }\end{array}$} & Distal ascending aorta may be sub-optimally visualized \\
\hline & & Difficult to reproduce images for serial monitoring \\
\hline \multirow[t]{2}{*}{ Multidetector CT (MDCT) } & All segments of aorta well visualized & Radiation exposure \\
\hline & $\begin{array}{l}\text { Contrast enhanced studies very accurate for } \\
\text { measurements }\end{array}$ & Often done with iodinated contrast \\
\hline $\begin{array}{l}\text { Magnetic resonance } \\
\text { imaging (MRI) }\end{array}$ & Often no need for iodinated contrast & May not be possible in patients with certain devices \\
\hline
\end{tabular}

centers. Ideally, serial monitoring should be performed with the same imaging modality to allow for direct comparisons of dimensions over time. If possible, interpretation of the studies by the same reader further minimizes variability in the reads over time. While this may not be logistically feasible, clearly reporting the method used for measurements can help make future reads more consistent.

Several studies have assessed how imaging modalities compare to each other for aortic measurements. It has been stated that the best agreement between TTE and CTA is with TTE end diastolic leading edge to leading edge measurements and CTA diastolic inner edge to inner edge measurements for the sinus and ascending aorta (77). However, the use of inner edge to inner edge measurements on echocardiography has also previously been shown to be similar to CT $(8,77)$ and MRI $(5,77)$ inner edge to inner edge measurements. In a study which performed head-to-head comparisons of thoracic aortic aneurysm measurements by TTE and MDCT within 7 days of each other in 50 patients with known ascending aortic dilation or aneurysm (92), echocardiography underestimated all measurements except for the ascending aorta using the standard techniques of end diastolic leading edge to leading edge by echocardiography and inner edge to inner edge by MDCT. Use of inner edge to inner edge by echocardiography was on average $2 \mathrm{~mm}$ less than leading edge to leading edge and thus further underestimated dimensions (92).

Multiple studies have compared echocardiographic and CT measurements with direct surgical annular sizing. In a study of 26 patients, end-systolic echocardiographic measurements (both by TTE and TEE) were shown to have the best correlation to intraoperative sizing, with effective CT diameter, defined as the diameter of a disk with the same circumference-based area of the annulus, having a higher correlation with direct sizing compared to minimum, maximum, or mean diameters (93). All of these measurements also had high cross-correlation. In those with an oval shaped annulus, TTE underestimated size, while TEE and CT were more accurate (93). For pronounced oval annular shape, CT was the most reliable imaging method. A subsequent larger study of 227 patients comparing preoperative CTA and TEE images with annular sizing showed that TEE may underestimate annular diameter, especially when deriving measurements from 2D images (94). Use of 3D multiplanar reconstruction can help address this issue and allow for more accurate measurements (94). CTA, on the other hand, was seen in this study to often overestimate annular diameter; the combination of TEE and CT measurements had the best predictive power (94). Unfortunately, similar studies comparing dimensions by imaging versus surgical sizing in other in parts of the thoracic aorta are not available. 


\section{Conclusions}

Serial imaging of the thoracic aorta by echocardiography, cardiac CT, and MRI is commonly performed for various conditions associated with thoracic aortic ectasia, and precise measurements are crucial in identifying when patients should be considered for surgery to prevent serious complications, such as aortic dissection or rupture. There is still considerable variability in the various methods used for measuring thoracic aortic dimensions. A multimodality imaging strategy incorporating both echocardiography and tomographic imaging (either cardiac CT or MRI) is ideal for many patients to definitively establish thoracic aortic dimensions and for serial monitoring. Both echocardiographic studies and tomographic imaging should make use of $3 \mathrm{D}$ and multiplanar techniques to obtain the most accurate thoracic aortic measurements. Until clear recommendations are available to standardize imaging protocols across institutions, it is critical for cardiovascular imaging specialists to be explicit about how thoracic aorta measurements are derived to allow for reproducibility in future studies.

\section{Acknowledgments}

Funding: None.

\section{Footnote}

Provenance and Peer Review: This article was commissioned by the editorial office, Cardiovascular Diagnosis and Therapy for the series "Heart Valve Disease". The article has undergone external peer review.

Conflicts of Interest: All authors have completed the ICMJE uniform disclosure form (available at http://dx.doi. org/10.21037/cdt-20-279). The series "Heart Valve Disease" was commissioned by the editorial office without any funding or sponsorship. BX served as the unpaid Guest Editor of the series. The authors have no other conflicts of interest to declare.

Ethical Statement: The authors are accountable for all aspects of the work in ensuring that questions related to the accuracy or integrity of any part of the work are appropriately investigated and resolved.

Open Access Statement: This is an Open Access article distributed in accordance with the Creative Commons Attribution-NonCommercial-NoDerivs 4.0 International License (CC BY-NC-ND 4.0), which permits the noncommercial replication and distribution of the article with the strict proviso that no changes or edits are made and the original work is properly cited (including links to both the formal publication through the relevant DOI and the license). See: https://creativecommons.org/licenses/by-nc-nd/4.0/.

\section{References}

1. Goldstein SA, Evangelista A, Abbara S, et al. Multimodality Imaging of Diseases of the Thoracic Aorta in Adults:

From the American Society of Echocardiography and the European Association of Cardiovascular Imaging. J Am Soc Echocardiogr 2015;28:119-82.

2. Hiratzka LF, Bakris GL, Beckman JA, et al. 2010 ACCF/ AHA/AATS/ACR/ASA/SCA/SCAI/SIR/STS/SVM guidelines for the diagnosis and management of patients with thoracic aortic disease: Executive summary: A report of the American College of Cardiology Foundation/ American Heart Association task force on practice guidelines, American Association for Thoracic Surgery, American College of Radiology, American Stroke Association. Circulation 2010;121:e266-e369.

3. Xu B, Kocyigit D, Betancor J, et al. Sinus of Valsalva Aneurysms: A State-of-the-Art Imaging Review. J Am Soc Echocardiogr 2020;33:295-312.

4. Vriz O, Driussi C, Bettio M, et al. Aortic Root Dimensions and Stiffness in Healthy Subjects. Am J Cardiol 2013;112:1224-9.

5. Burman ED, Keegan J, Kilner PJ. Aortic root measurement by cardiovascular magnetic resonance: specification of planes and lines of measurement and corresponding normal values. Circ Cardiovasc Imaging 2008;1:104-13.

6. Devereux RB, de Simone G, Arnett DK, et al. Normal Limits in Relation to Age, Body Size and Gender of Two-Dimensional Echocardiographic Aortic Root Dimensions in Persons $\geq 15$ Years of Age. Am J Cardiol 2012;110:1189-94.

7. Hager A, Kaemmerer H, Rapp-Bernhardt U, et al. Diameters of the thoracic aorta throughout life as measured with helical computed tomography. J Thorac Cardiovasc Surg 2002;123:1060-6.

8. Lin FY, Devereux RB, Roman MJ, et al. Assessment of the thoracic aorta by multidetector computed tomography: Age- and sex-specific reference values in adults without 
evident cardiovascular disease. J Cardiovasc Comput Tomogr 2008;2:298-308.

9. Lam CSP, Xanthakis V, Sullivan LM, et al. Aortic root remodeling over the adult life course: Longitudinal data from the framingham heart study. Circulation 2010;122:884-90.

10. Vasan RS, Larson MG, Benjamin EJ, Levy D. Echocardiographic reference values for aortic root size: The Framingham Heart Study. J Am Soc Echocardiogr 1995;8:793-800.

11. Daimon M, Watanabe $H$, Abe $Y$, et al. Normal values of echocardiographic parameters in relation to age in a healthy Japanese population - The JAMP study. Circ J 2008;72:1859-66.

12. Vasan RS, Larson MG, Levy D. Determinants of echocardiographic aortic root size: The Framingham Heart Study. Circulation 1995;91:734-40.

13. Erbel R, Aboyans V, Boileau C, et al. 2014 ESC Guidelines on the diagnosis and treatment of aortic diseases: Document covering acute and chronic aortic diseases of the thoracic and abdominal aorta of the adult. The Task Force for the Diagnosis and Treatment of Aortic Diseases of the European Society of Cardiology (ESC). Eur Heart J 2014;35:2873-926.

14. Hiratzka LF, Creager MA, Isselbacher EM, et al. Surgery for Aortic Dilatation in Patients with Bicuspid Aortic Valves: A Statement of Clarification From the American College of Cardiology/American Heart Association Task Force on Clinical Practice Guidelines. J Am Coll Cardiol 2016;67:724-31.

15. Johnston KW, Rutherford RB, Tilson MD, et al. Suggested standards for reporting on arterial aneurysms. J Vasc Surg 1991;13:452-8.

16. Isselbacher EM. Thoracic and abdominal aortic aneurysms. Circulation 2005;111:816-28.

17. Davies RR, Kaple RK, Mandapati D, et al. Natural history of ascending aortic aneurysms in the setting of an unreplaced bicuspid aortic valve. Ann Thorac Surg 2007;83:1338-44.

18. Davies RR, Goldstein LJ, Coady MA, et al. Yearly rupture or dissection rates for thoracic aortic aneurysms: simple prediction based on size. Ann Thorac Surg 2002;73:17-27; discussion 27-8.

19. Roman MJ, Devereux RB, Kramer-Fox R, et al. Twodimensional echocardiographic aortic root dimensions in normal children and adults. Am J Cardiol 1989;64:507-12.

20. Masri A, Kalahasti V, Svensson LG, et al. Aortic CrossSectional Area/Height Ratio and Outcomes in Patients with Bicuspid Aortic Valve and a Dilated Ascending Aorta. Circ Cardiovasc Imaging 2017;10:e006249.

21. Masri A, Kalahasti V, Svensson LG, et al. Aortic CrossSectional Area/Height Ratio and Outcomes in Patients with a Trileaflet Aortic Valve and a Dilated Aorta. Circulation 2016;134:1724-37.

22. Rosamond W, Flegal K, Furie K, et al. Heart disease and stroke statistics--2008 update: a report from the American Heart Association Statistics Committee and Stroke Statistics Subcommittee. Circulation 2008;117:e25-146. Erratum in: Circulation. 2010 Jul 6;122(1):e10. Kissela, Bret [corrected to Kissela, Brett].

23. Nistri S, Basso C, Marzari C, et al. Frequency of bicuspid aortic valve in young male conscripts by echocardiogram. Am J Cardiol 2005;96:718-21.

24. Tutar E, Ekici F, Atalay S, et al. The prevalence of bicuspid aortic valve in newborns by echocardiographic screening. Am Heart J 2005;150:513-5.

25. Basso C, Boschello M, Perrone C, et al. An echocardiographic survey of primary school children for bicuspid aortic valve. Am J Cardiol 2004;93:661-3.

26. Gurvitz M, Chang RK, Drant S, et al. Frequency of aortic root dilation in children with a bicuspid aortic valve. Am J Cardiol 2004;94:1337-40.

27. Hahn RT, Roman MJ, Mogtader AH, et al. Association of aortic dilation with regurgitant, stenotic and functionally normal bicuspid aortic valves. J Am Coll Cardiol 1992;19:283-8.

28. Nistri S, Sorbo MD, Marin M, et al. Aortic root dilatation in young men with normally functioning bicuspid aortic valves. Heart 1999;82:19-22.

29. Ferencik M, Pape LA. Changes in size of ascending aorta and aortic valve function with time in patients with congenitally bicuspid aortic valves. Am J Cardiol 2003;92:43-6.

30. Della Corte A, Bancone C, Quarto C, et al. Predictors of ascending aortic dilatation with bicuspid aortic valve: a wide spectrum of disease expression. Eur J Cardiothorac Surg 2007;31:397-404; discussion 404-5.

31. Michelena HI, Khanna AD, Mahoney D, et al. Incidence of aortic complications in patients with bicuspid aortic valves. JAMA 2011;306:1104-12.

32. Opotowsky AR, Perlstein T, Landzberg MJ, et al. A shifting approach to management of the thoracic aorta in bicuspid aortic valve. J Thorac Cardiovasc Surg 2013;146:339-46.

33. Nataatmadja M, West M, West J, et al. Abnormal extracellular matrix protein transport associated with 
increased apoptosis of vascular smooth muscle cells in marfan syndrome and bicuspid aortic valve thoracic aortic aneurysm. Circulation 2003;108 Suppl 1:II329-34.

34. de Sa M, Moshkovitz Y, Butany J, et al. Histologic abnormalities of the ascending aorta and pulmonary trunk in patients with bicuspid aortic valve disease: clinical relevance to the ross procedure. J Thorac Cardiovasc Surg 1999;118:588-94.

35. Bauer M, Pasic M, Meyer R, et al. Morphometric analysis of aortic media in patients with bicuspid and tricuspid aortic valve. Ann Thorac Surg 2002;74:58-62.

36. Bonderman D, Gharehbaghi-Schnell E, Wollenek G, et al. Mechanisms underlying aortic dilatation in congenital aortic valve malformation. Circulation 1999;99:2138-43.

37. Schmid FX, Bielenberg K, Schneider A, et al. Ascending aortic aneurysm associated with bicuspid and tricuspid aortic valve: involvement and clinical relevance of smooth muscle cell apoptosis and expression of cell death-initiating proteins. Eur J Cardiothorac Surg 2003;23:537-43.

38. Fedak PWM, de Sa MPL, Verma S, et al. Vascular matrix remodeling in patients with bicuspid aortic valve malformations: implications for aortic dilatation. J Thorac Cardiovasc Surg 2003;126:797-806.

39. Boyum J, Fellinger EK, Schmoker JD, et al. Matrix metalloproteinase activity in thoracic aortic aneurysms associated with bicuspid and tricuspid aortic valves. J Thorac Cardiovasc Surg 2004;127:686-91.

40. Ikonomidis JS, Jones JA, Barbour JR, et al. Expression of matrix metalloproteinases and endogenous inhibitors within ascending aortic aneurysms of patients with bicuspid or tricuspid aortic valves. J Thorac Cardiovasc Surg 2007;133:1028-36.

41. Koullias GJ, Korkolis DP, Ravichandran P, et al. Tissue microarray detection of matrix metalloproteinases, in diseased tricuspid and bicuspid aortic valves with or without pathology of the ascending aorta. Eur J Cardiothorac Surg 2004;26:1098-103.

42. LeMaire SA, Wang X, Wilks JA, et al. Matrix metalloproteinases in ascending aortic aneurysms: bicuspid versus trileaflet aortic valves. J Surg Res 2005;123:40-8.

43. Dore A, Brochu MC, Baril JF, et al. Progressive dilation of the diameter of the aortic root in adults with a bicuspid aortic valve. Cardiol Young 2003;13:526-31.

44. La Canna G, Ficarra E, Tsagalau E, et al. Progression rate of ascending aortic dilation in patients with normally functioning bicuspid and tricuspid aortic valves. Am J Cardiol 2006;98:249-53.

45. Novaro GM, Griffin BP. Congenital bicuspid aortic valve and rate of ascending aortic dilatation. Am J Cardiol 2004;93:525-6.

46. Holmes KW, Lehmann CU, Dalal D, et al. Progressive dilation of the ascending aorta in children with isolated bicuspid aortic valve. Am J Cardiol 2007;99:978-83.

47. Shimada I, Rooney SJ, Pagano D, et al. Prediction of thoracic aortic aneurysm expansion: validation of formulae describing growth. Ann Thorac Surg 1999;67:1968-70; discussion 1979-80.

48. Coady MA, Rizzo JA, Hammond GL, et al. What is the appropriate size criterion for resection of thoracic aortic aneurysms? J Thorac Cardiovasc Surg 1997;113:476-91; discussion 489-91.

49. Yasuda H, Nakatani S, Stugaard M, et al. Failure to prevent progressive dilation of ascending aorta by aortic valve replacement in patients with bicuspid aortic valve: comparison with tricuspid aortic valve. Circulation 2003;108 Suppl 1:II291-4.

50. Svensson LG, Kim KH, Lytle BW, et al. Relationship of aortic cross-sectional area to height ratio and the risk of aortic dissection in patients with bicuspid aortic valves. J Thorac Cardiovasc Surg 2003;126:892-3.

51. Neri E, Barabesi L, Buklas D, et al. Limited role of aortic size in the genesis of acute type A aortic dissection. Eur J Cardiothorac Surg 2005;28:857-63.

52. Pape LA, Tsai TT, Isselbacher EM, et al. Aortic diameter $>$ or $=5.5 \mathrm{~cm}$ is not a good predictor of type A aortic dissection: observations from the International Registry of Acute Aortic Dissection (IRAD). Circulation 2007;116:1120-7.

53. Edwards WD, Leaf DS, Edwards JE. Dissecting aortic aneurysm associated with congenital bicuspid aortic valve. Circulation 1978;57:1022-5.

54. American College of Cardiology/American Heart Association Task Force on Practice Guidelines, Society of Cardiovascular Anesthesiologists, Society for Cardiovascular Angiography and Interventions, et al. ACC/AHA 2006 guidelines for the management of patients with valvular heart disease: a report of the American College of Cardiology/American Heart Association Task Force on Practice Guidelines (writing committee to revise the 1998 Guidelines for the Management of Patients With Valvular Heart Disease): developed in collaboration with the Society of Cardiovascular Anesthesiologists: endorsed by the Society for Cardiovascular Angiography and Interventions and the Society of Thoracic Surgeons. Circulation 2006;114:e84-231.

55. Milewicz DM, Dietz HC, Miller DC. Treatment of aortic 
disease in patients with Marfan syndrome. Circulation 2005;111:e150-7.

56. Jondeau G, Detaint D, Tubach F, et al. Aortic event rate in the Marfan population: a cohort study. Circulation 2012;125:226-32.

57. Loeys BL, Chen J, Neptune ER, et al. A syndrome of altered cardiovascular, craniofacial, neurocognitive and skeletal development caused by mutations in TGFBR1 or TGFBR2. Nat Genet 2005;37:275-81.

58. Loeys BL, Schwarze U, Holm T, et al. Aneurysm syndromes caused by mutations in the TGF- $\beta$ receptor. $\mathrm{N}$ Engl J Med 2006;355:788-98.

59. Gupta PA, Putnam EA, Carmical SG, et al. Ten novel FBN2 mutations in congenital contractural arachnodactyly: delineation of the molecular pathogenesis and clinical phenotype. Hum Mutat 2002;19:39-48.

60. Gupta PA, Wallis DD, Chin TO, et al. FBN2 mutation associated with manifestations of Marfan syndrome and congenital contractural arachnodactyly. J Med Genet 2004;41:e56.

61. Lang RM, Bierig M, Devereux RB, et al.

Recommendations for chamber quantification. Eur J Echocardiogr 2006;7:79-108.

62. Evangelista A, Flachskampf FA, Erbel R, et al. Echocardiography in aortic diseases: EAE recommendations for clinical practice. Eur J Echocardiogr 2010;11:645-58.

63. Schnittger I, Gordon EP, Fitzgerald PJ, et al. Standardized intracardiac measurements of two-dimensional echocardiography. J Am Coll Cardiol 1983;2:934-8.

64. Mirea O, Maffessanti F, Gripari P, et al. Effects of aging and body size on proximal and ascending aorta and aortic arch: inner edge-to-inner edge reference values in a large adult population by two-dimensional transthoracic echocardiography. J Am Soc Echocardiogr 2013;26:419-27.

65. Kothavale AA, Yeon SB, Manning WJ. A systematic approach to performing a comprehensive transesophageal echocardiogram. A call to order. BMC Cardiovasc Disord 2009;9:18.

66. ASE's Comprehensive Echocardiography - 2nd Edition. Accessed January 10, 2021. Available online: https://www.elsevier.com/books/ases-comprehensiveechocardiography/lang/978-0-323-26011-4

67. Hagendorff A, Stoebe S, Tayal B. A systematic approach to 3D echocardiographic assessment of the aortic root. Glob Cardiol Sci Pract 2018;2018:12.

68. Mediratta A, Addetia K, Medvedofsky D, et al. 3D echocardiographic analysis of aortic annulus for transcatheter aortic valve replacement using novel aortic valve quantification software: Comparison with computed tomography. Echocardiography 2017;34:690-9.

69. Sebastià C, Pallisa E, Quiroga S, et al. Aortic Dissection: Diagnosis and Follow-up with Helical CT. RadioGraphics 1999; 19:45-60.

70. Vernhet H, Serfaty JM, Serhal M, et al. Abdominal CT Angiography Before Surgery as a Predictor of Postoperative Death in Acute Aortic Dissection. AJR Am J Roentgenol 2004;182:875-9.

71. Roos JE, Willmann JK, Weishaupt D, et al. Thoracic aorta: motion artifact reduction with retrospective and prospective electrocardiography-assisted multi-detector row CT. Radiology 2002;222:271-7.

72. Picano E, Vañó E, Rehani MM, et al. The appropriate and justified use of medical radiation in cardiovascular imaging: a position document of the ESC Associations of Cardiovascular Imaging, Percutaneous Cardiovascular Interventions and Electrophysiology. Eur Heart J 2014;35:665-72.

73. Katzberg RW, Lamba R. Contrast-induced nephropathy after intravenous administration: fact or fiction? Radiol Clin North Am 2009;47:789-800,

74. Svensson LG, Adams DH, Bonow RO, et al. Aortic Valve and Ascending Aorta Guidelines for Management and Quality Measures. Ann Thorac Surg 2013;95:S1-66.

75. Muraru D, Maffessanti F, Kocabay G, et al. Ascending aorta diameters measured by echocardiography using both leading edge-to-leading edge and inner edge-to-inner edge conventions in healthy volunteers. Eur Heart J Cardiovasc Imaging 2014;15:415-22.

76. Mao SS, Ahmadi N, Shah B, et al. Normal thoracic aorta diameter on cardiac computed tomography in healthy asymptomatic adults: impact of age and gender. Acad Radiol 2008;15:827-34.

77. Rodríguez-Palomares JF, Teixidó-Tura G, Galuppo V, et al. Multimodality Assessment of Ascending Aortic Diameters: Comparison of Different Measurement Methods. J Am Soc Echocardiogr 2016;29:819-826.e4.

78. Torres FS, Windram JD, Bradley TJ, et al. Impact of asymmetry on measurements of the aortic root using cardiovascular magnetic resonance imaging in patients with a bicuspid aortic valve. Int J Cardiovasc Imaging 2013;29:1769-77.

79. Hartnell GG. Imaging of aortic aneurysms and dissection: CT and MRI. J Thorac Imaging 2001;16:35-46.

80. Holloway BJ, Rosewarne D, Jones RG. Imaging of 
thoracic aortic disease. Br J Radiol 2011;84:S338-54.

81. Chavhan GB, Babyn PS, Jankharia BG, et al. Steady-state MR imaging sequences: physics, classification, and clinical applications. Radiographics 2008;28:1147-60.

82. François CJ, Tuite D, Deshpande V, et al. Unenhanced MR Angiography of the Thoracic Aorta: Initial Clinical Evaluation. AJR Am J Roentgenol 2008;190:902-6.

83. Kramer CM, Barkhausen J, Bucciarelli-Ducci C, et al. Standardized cardiovascular magnetic resonance imaging (CMR) protocols: 2020 update. J Cardiovasc Magn Reson 2020;22:17.

84. Hoey ETD, Ganeshan A, Puni R, et al. Fresh Blood Imaging of the Peripheral Vasculature: An Emerging Unenhanced MR Technique. AJR Am J Roentgenol 2010;195:1444-8.

85. Prince MR. Gadolinium-enhanced MR aortography. Radiology 1994;191:155-64.

86. Srichai MB, Kim S, Axel L, et al. Non-GadoliniumEnhanced 3-Dimensional Magnetic Resonance Angiography for the Evaluation of Thoracic Aortic Disease. Tex Heart Inst J 2010;37:58-65.

87. Krishnam MS, Tomasian A, Deshpande V, et al. Noncontrast 3D steady-state free-precession magnetic resonance angiography of the whole chest using nonselective radiofrequency excitation over a large field of view: comparison with single-phase 3D contrastenhanced magnetic resonance angiography. Invest Radiol 2008;43:411-20.

88. Amano Y, Takahama K, Kumita S. Non-contrast-enhanced MR angiography of the thoracic aorta using cardiac and

Cite this article as: Mani P, Reyaldeen R, Xu B. Multimodality imaging assessment of bicuspid aortic valve disease, thoracic aortic ectasia, and thoracic aortic aneurysmal disease. Cardiovasc Diagn Ther 2021;11(3):896-910. doi: 10.21037/cdt20-279 navigator-gated magnetization-prepared three-dimensional steady-state free precession. J Magn Reson Imaging 2008;27:504-9.

89. MRI of the thoracic aorta. Accessed December 27, 2020. Available online: https://appliedradiology.com/ communities/ct-imaging/mri-of-the-thoracic-aorta

90. Cigarroa JE, Isselbacher EM, Desanctis RW, et al. Diagnostic Imaging in the Evaluation of Suspected Aortic Dissection - Old Standards and New Directions. N Engl J Med 1993;328:35-43.

91. Asch FM, Yuriditsky E, Prakash SK, et al. The Need for Standardized Methods for Measuring the Aorta: Multimodality Core Lab Experience from the GenTAC Registry. JACC Cardiovasc Imaging 2016;9:219-26.

92. Ghulam Ali S, Fusini L, Dalla Cia A, et al. Technological Advancements in Echocardiographic Assessment of Thoracic Aortic Dilatation: Head to Head Comparison Among Multidetector Computed Tomography, 2-Dimensional, and 3-Dimensional Echocardiography Measurements. J Thorac Imaging 2018;33:232-9.

93. Kempfert J, Van Linden A, Lehmkuhl L, et al. Aortic annulus sizing: echocardiographic versus computed tomography derived measurements in comparison with direct surgical sizing. Eur J Cardiothorac Surg 2012;42:627-33.

94. Wang H, Hanna JM, Ganapathi A, et al. Comparison of aortic annulus size by transesophageal echocardiography and computed tomography angiography with direct surgical measurement. Am J Cardiol 2015;115:1568-73. 